\title{
Different Phenotypes of Non-Steroidal Anti-Inflammatory Drug Hypersensitivity during Childhood
}

\author{
Ozlem Cavkaytar $^{\mathrm{a}}$ Ebru Arik Yilmaz ${ }^{\mathrm{a}}$ Betul Karaatmaca ${ }^{\mathrm{a}}$ Betul Buyuktiryaki ${ }^{\mathrm{a}}$ \\ Cansın Sackesen $^{\mathrm{a}, \mathrm{b}}$ Bulent E. Sekerel ${ }^{\mathrm{a}}$ Ozge Soyer $^{\mathrm{a}}$ \\ a Department of Pediatric Allergy, Hacettepe University School of Medicine, Ankara, and ${ }^{b}$ Division of Pediatric \\ Allergy, Koc University School of Medicine, Istanbul, Turkey
}

\section{Key Words}

Paediatric patients - Cross-reactivity - Drug hypersensitivity . Non-steroidal anti-inflammatory drugs $\cdot$ Selective responders

\begin{abstract}
Background: Although non-steroidal anti-inflammatory drug hypersensitivity (NSAID-H) has been widely studied in adults, there is still a lack of data regarding the features and phenotypes of NSAID-H in children. Our aim was to define risk factors and different phenotypes according to clinical patterns. Methods: Patients with a history of reaction to any NSAIDs referred between January 2012 and October 2014 were included. After completing a European Network for Drug Allergy (ENDA) questionnaire, initial skin and/or oral provocation tests (OPTs) were performed for the offending drug. Additional OPTs were done with aspirin in case of NSAID-H to determine cross-reactivity. NSAID-hypersensitive patients were defined as being either a selective responder (SR) or cross-intolerant (Cl) and further categorized according to either the ENDA/GA 2 LEN classification or an alternative scheme by Caimmi et al. [Int Arch Allergy Immunol 2012;159:306-312]. Results: Among 121 patients [58.7\%
\end{abstract}

male, average age 7.8 years (4.7-10.8)] with 161 NSAID-related reactions, 110 patients with 148 reactions were assessed. NSAID-H was diagnosed in 30 (27\%) patients with 37 (25\%) reactions. Multivariate regression analysis revealed that an immediate-type reaction and respiratory symptoms during the reaction increased the risk of a reproducible NSAID-related reaction (OR 3.508, 95\% Cl 1.42-8.7, $\mathrm{p}=0.007$; OR 3.951, $95 \% \mathrm{Cl} 1.33-11.77, \mathrm{p}=0.014$, respectively). Additional OPTs revealed $13 \mathrm{SRs}$ and $14 \mathrm{Cls}$. A family history of allergic disease was more frequent in Cls compared to SRs (57.1 vs. $15.4 \%$, $\mathrm{p}=0.031$ ). Reactions belonging to $\mathrm{Cls}$ were more frequently characterized by angioedema compared to those of SRs (81.3 vs. $46.2 \%, p=0.019$ ). SRs and Cls were further classified as single NSAID-induced urticaria/angioedema and/or anaphylaxis $(n=13)$, NSAID-induced urticaria/angioedema $(n=$ 7), NSAID-exacerbated cutaneous disease $(n=2)$ and NSAIDexacerbated respiratory disease $(n=1)$. Four $\mathrm{Cls}$ could not be categorized according to either classification system. One SR could not be categorized according to ENDA/GA²LN. Conclusion: During childhood, NSAID-H exhibits different phenotypes and the majority of them can be categorized with current classification systems; however, classifications based on adult data may not exactly fit NSAID-H in paediatric patients.

(c) 2015 S. Karger AG, Basel

\section{KARGER 125}

(c) 2015 S. Karger AG, Base

1018-2438/15/1673-0211\$39.50/0 


\section{Introduction}

Non-steroidal anti-inflammatory drugs (NSAIDs) are one of the most frequently prescribed group of drugs in the treatment of children and adults [1]. In order to relieve inflammation, NSAIDs act through the inhibition of the cyclooxygenase (COX) enzyme and prostanoid (prostaglandin, thromboxane and prostacyclin) synthesis [2]. However, in susceptible individuals, this uniform mechanism may end up with clinical manifestations of the predominant type of NSAID hypersensitivity (NSAID-H) [3].

Current evidence indicates that NSAIDs are commonly involved in drug-related hypersensitivity reactions [4, 5]. The pathological mechanisms reveal two main patterns of patients with NSAID-H: cross-intolerants (CIs), who are hypersensitive to more than one chemically unrelated NSAID, and selective responders (SRs), who are hypersensitive to only one type of NSAID but tolerant to chemically unrelated NSAIDs [6].

For decades, researchers and clinicians have tended to categorize different phenotypes of NSAID-H based on the results of published epidemiologic studies [7-9]. In recent years, the European Academy of Allergy and Clinical Immunology Interest Group on Drug Allergy/ European Network for Drug Allergy (EAACI/ENDA) and the Global Allergy and Asthma European Network/ European Network on Hypersensitivity to Aspirin and Nonsteroidal Anti-Inflammatory Drugs (GA ${ }^{2} \mathrm{LEN} /$ HANNA) groups have further classified CIs into three subgroups and SRs into two subgroups [10]. In a Task Force published in 2013 by Kowalski et al. [3], the nomenclature for this classification system was updated as NSAID-exacerbated cutaneous disease (NECD), NSAID-exacerbated respiratory disease (NERD), NSAID-induced urticaria/angioedema (NIUA), single NSAID-induced urticaria/angioedema and/or anaphylaxis (SNIUA and/or SNIUAA), and single NSAID-induced delayed reactions (SNIDR). This classification system supports clinicians in diagnosing cases of suspected NSAID-H. Furthermore, categorization of these clinical phenotypes is an initial requirement in pharmacokinetic studies $[6,11]$.

The epidemiologic data for NSAID-H in childhood has increased over the last few years [12-14], but there is still a lack of data regarding the special features of NSAID$\mathrm{H}$ in children and adolescents. To date, the clinical phenotypes of NSAID-H have been investigated and classified in detail with a focus on adults $[7,9,11,15,16]$; however, the classifications may not be the same for paediatric patients. Therefore, we aimed to define the clinical characteristics of and risk factors for NSAID-H during childhood. Furthermore, we classified NSAIDrelated hypersensitivity reactions in the paediatric age group in comparison with the clinical phenotypes of NSAID-hypersensitive adults.

\section{Materials and Methods}

\section{Patients}

Children and adolescents who were referred to the Department of Pediatric Allergy at Hacettepe University, located in Ankara, Turkey, between January 2012 and October 2014 due to a history of NSAID-related suspected hypersensitivity reactions were included in the study. The study was conducted according to the Declaration of Helsinki; it was approved by the Ethics Committee of Hacettepe University and parents provided written informed consent. A European Network for Drug Allergy (ENDA) questionnaire was filled out regarding the suspected NSAID-related hypersensitivity reaction; in addition, the demographic and clinical features of the patients were noted. An 'immediate reaction' was defined as the occurrence of a reaction within $1 \mathrm{~h}$ of drug intake and a 'non-immediate reaction' referred to a reaction that occurred more than $1 \mathrm{~h}$ after drug intake [17]. Skin tests with metamizole were performed for patients with a history of metamizoleinduced hypersensitivity reaction. All the other patients without a severe anaphylaxis history with the culprit NSAID and the patients with a negative skin test with metamizole underwent oral provocation tests (OPTs) with the offending drug. The criteria for performing a diagnostic test were: (i) age $\geq 2$ years at the time of the diagnostic tests, (ii) being in a healthy state, with no symptoms of an acute illness or uncontrolled asthma and with a baseline forced expiratory volume in $1 \mathrm{~s}\left(\mathrm{FEV}_{1}\right)$ level $\geq 80 \%$ for patients capable of performing a spirometry, and (iii) not having had an initial reaction recalling a contraindication for performing a test with the culprit drug (e.g. in the case of Stevens-Johnson syndrome or toxic epidermal necrolysis, etc.) [18]. Diagnostic tests were performed in the clinical setting under strict medical supervision at least 6 weeks after the suspected NSAID-related hypersensitivity reaction [18]. The patients with a positive diagnostic test or with a history of severe anaphylaxis (grade 3 or more, according to the Systemic Reaction Grading System of the World Allergy Organization) [19] occurring within minutes after the intake of solely the culprit NSAID, which was confirmed with medical records, were classified as 'NSAID-hypersensitive'. NSAIDhypersensitive and tolerant patients were compared according to demographic and clinical features and baseline laboratory values. In addition, since a single patient might have more than one suspected reaction with more than one drug, the clinical features of individual reactions were also compared. With a further step the risk factors for an NSAID-related hypersensitivity reaction were determined.

In the event of a NSAID-related hypersensitivity, additional OPTs were done with aspirin to confirm or exclude cross-reactivity (as is recommended) $[3,20]$. If the patient had used aspirin as the culprit drug and was found to be aspirin-hypersensitive, ibuprofen was used for additional OPTs to determine whether or not 
cross-reactivity existed. Patients with NSAID-H were defined as SR or CI according to the results of extra OPTs. SRs and CIs were further categorized according to either the ENDA/GA ${ }^{2} \mathrm{LEN}$ classification $[3,10]$ or the alternative classification scheme of Caimmi et al. [9] (online suppl. table S1; for all online suppl. material, see www.karger.com/doi/10.1159/000438992) regarding clinical patterns of NSAID-related hypersensitivity reactions during severe anaphylactic reactions and OPTs. In order to classify the patients, the timing of the reaction and the existence of underlying atopy or concomitant allergic disease, chronic urticaria or chronic rhinosinusitis were taken into consideration. The diagnostic criteria for asthma, allergic rhinitis, food allergy, chronic urticaria and atopy are further detailed in the Methods section of the online supplementary material.

\section{Study Measurements}

Skin Test with Metamizole

Metamizole, a pyrazolone derivative that may also act through COX-1 inhibition as a potential cross-reactive drug with aspirin [21], is available in Turkey in an injectable form (Novalgin Ampul, $1 \mathrm{~g} / 2 \mathrm{ml}$; Sanofi Aventis, Paris, France). A skin prick test with metamizole was initially performed with a concentration of $0.1 \mathrm{mg} / \mathrm{ml}$. In the event of a negative skin prick test result, intradermal tests were performed with 0.01 and $0.1 \mathrm{mg} / \mathrm{ml}$ of metamizole, in that order, as described previously [22]. A skin prick test or intradermal test was considered positive if the induration of the drug was at least $3 \mathrm{~mm}$ higher than that of saline at 15 or $20 \mathrm{~min}$ after the administration of metamizole, respectively, in the presence of a positive histamine response. If the intradermal test was negative, an OPT with metamizole was performed for these patients.

OPTs with NSAIDs

OPTs with the culprit NSAIDs were performed (in accordance with ENDA guidelines) in four or five divided doses, starting from low doses and given in an increasing order at 1.5-hour intervals until the occurrence of a positive reaction or until the cumulative single therapeutic dose appropriate for the patient's age and weight was achieved [18]. Immediately before and $30 \mathrm{~min}$ after each dose during OPT, a spirometry test was repeated and $\mathrm{FEV}_{1}$ was measured in patients older than 6 years of age who were capable of performing a spirometry. The doses were determined according to previously approved protocols $[4,22,23]$ (online suppl. table S2). Patients were followed up for $6 \mathrm{~h}$ after the end of the OPTs. The patients and their parents were informed about the symptoms of a positive OPT and after the 6-hour follow-up period they were advised to call and readmit for an additional $48 \mathrm{~h}$ in the event of the occurrence of possible allergic symptoms, as previously described [24].

A positive OPT was defined as the occurrence of any of the following objective physical findings related to a hypersensitivity reaction: (i) cutaneous symptoms (urticaria, angioedema and/or conjunctivitis), (ii) symptoms related to the cardiovascular system (change in heart rate, hypotension, etc.), (iii) upper or lower respiratory tract symptoms (rhinorrhoea, sneezing, nasal congestion, cough, dyspnoea) or a $>15 \%$ decrease in $\mathrm{FEV}_{1}$ during OPT [23]. In the event of a positive reaction, the test was terminated and the patients were treated with antihistamines, methylprednisolone or adrenaline, as needed, and each patient was supervised until the symptoms were completely resolved.

Different Phenotypes of NSAID-H

\section{Statistical Analysis}

The statistical analyses were carried out using the Statistical Package for Social Sciences (SPSS) 21.0 software (SPSS Inc., Chicago, Ill., USA). Since a patient might have a drug hypersensitivity reaction (DHR) history with more than one NSAID, the data related to the demographic and clinical characteristics of each patient and the data related to the features of each reaction were recorded in two different databases. Descriptive data for categorical and numerical variables with non-normal and normal distributions were rendered as frequencies, median (interquartile range) and mean \pm standard deviation, respectively. Comparisons between the groups were established via either a $\chi^{2}$ test, Fisher's exact test or Kruskal-Wallis test. Univariate and multivariate logistic regression analyses were used to define the independent risk factors for either personal NSAID-H or for a reproducible NSAID-related reaction. A p value $<0.5$ was considered statistically significant.

\section{Results}

One hundred and twenty-one patients $[58.7 \%$ male, median age 7.8 years (interquartile range $4.7-10.8$ )], with 161 suspected NSAID-related reactions were admitted to our department between January 2012 and October 2014. One hundred and ten patients (91\%) with 148 reactions (92\%) were assessed (fig. 1). The demographic characteristics of the study participants and the clinical features during their reactions did not differ from the 11 patients who were not assessed (data not shown). As a result of 173 OPTs and 13 skin tests performed for diagnostic purposes, 30 ( $27 \%$ of all patients) patients [ $70 \%$ male, median age 9.4 years (5.4-12.9)] with 37 reactions $(25 \%$ of all suspected reactions) were defined as 'NSAID hypersensitive'. Among the NSAID-hypersensitive patients, the majority $(n=23)$ were diagnosed via OPTs, 1 patient was diagnosed via a skin test with the culprit drug. In 6 patients the diagnosis of NSAID-H was based on the history of severe anaphylaxis that occurred within minutes after the consumption of solely the culprit NSAID that was confirmed by medical records. The patients with NSAID-H did not differ significantly from NSAID-tolerant participants in terms of age, gender, atopy, asthma, allergic rhinitis or chronic urticaria, eosinophil counts or total IgE levels (data not shown).

Regarding suspected drug reactions, none of the participants had reactions occurring more than $24 \mathrm{~h}$ after the culprit NSAID intake or reactions recalling fixed drug eruption, toxic epidermal necrolysis or Stevens-Johnson syndrome. Angioedema and signs and symptoms involving the respiratory system were seen more frequently during reactions of reproducible NSAID-H compared to NSAID-tolerant reactions ( 78.4 vs. $56.8 \%, p=0.019$, and 
Fig. 1. Flow chart of the study.

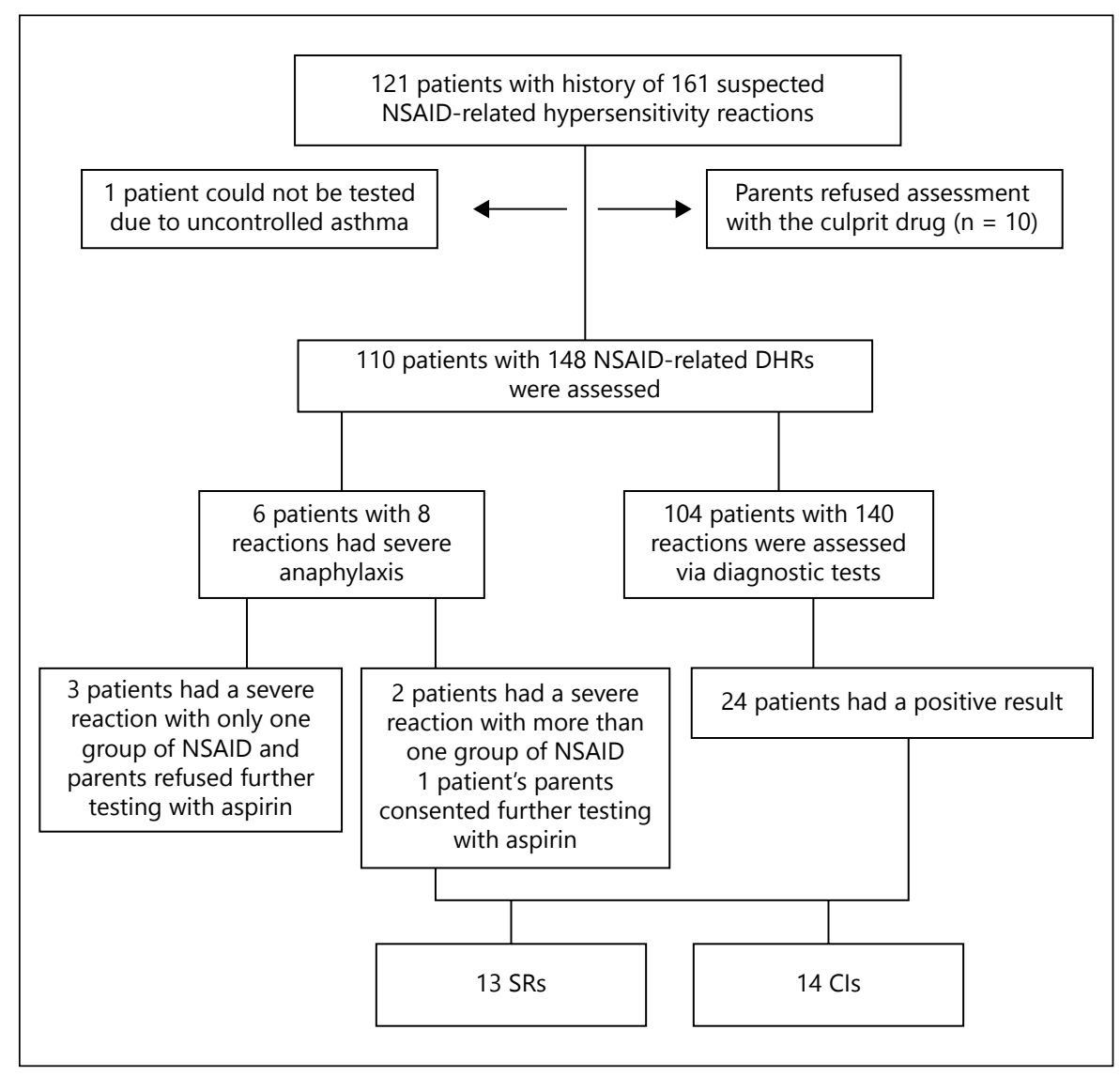

29.7 vs. $6.3 \%, \mathrm{p}<0.001$, respectively). Patients experienced immediate reactions $(\leq 1 \mathrm{~h})$ more frequently during reactions of reproducible NSAID-H ( 81.1 vs. $41.4 \%, \mathrm{p}<$ 0.001 ), whereas the rate of use of antihistamines or corticosteroids for the treatment of suspected reactions were similar between NSAID-tolerant and hypersensitive reactions (table 1a). In a multivariate logistic regression analysis, an NSAID-related immediate type of reaction and respiratory system involvement during the reaction increased the risk of a reproducible NSAID-related hypersensitivity reaction (OR 4.175, 95\% CI 1.62-10.72, p = 0.003 , and OR 4.038, 95\% CI 1.35-12.08, p = 0.013, respectively; table $1 \mathrm{~b}$ ). In 1 patient (patient 7; table 2), during an OPT with ibuprofen, the only positive sign was a $>15 \%$ decrease in $\mathrm{FEV}_{1}$, which manifested after taking $40 \%$ of the therapeutic dose. The OPT was immediately terminated and the patient was treated with salbutamol and systemic corticosteroid. The same response was observed when the patient was rechallenged with ibuprofen 4 weeks after the initial test to confirm the diagnosis; however, the patient did not react to aspirin, so he was classified as SR. During another six OPTs in 4 patients (patients 5, 23, 24 and 27) a greater than 15\% decrease in $\mathrm{FEV}_{1}$ was seen with the other clinical manifestations (table 2 ). As a result of 39 positive OPTs, only 2 patients required adrenaline treatment, and both responded quickly to the injection.

As a result of further testing of NSAID-hypersensitive patients with aspirin, SRs and CIs were determined (fig. 1; table 2). Three patients (patients 2, 16, 17; table 2) with a severe anaphylactic reaction history related to a single NSAID [19] could not be tested with aspirin (which is a strong COX-1 inhibitor) since their parents did not consent. Therefore, they could not be included in further classification. Two other patients with severe anaphylactic reactions had a history with more than one chemically unrelated NSAID, meaning they did not need a further test with aspirin. One patient with a severe reaction history and all the other NSAID-hypersensitive patients underwent a challenge with aspirin to find out the rate of cross-reactivity. In total, there were 13 SRs and 14 CIs (fig. 1).

The demographic and clinical features of either SRs or CIs did not differ, with the exception of a family history 
Table 1. Clinical features of suspected NSAID-related reactions and risk factors for reproducible NSAID-H

a Clinical features of suspected NSAID-related reactions according to reproducible NSAID-H

\begin{tabular}{|c|c|c|c|}
\hline Clinical features in patient history & NSAID hypersensitive $(\mathrm{n}=37)$ & NSAID tolerant $(\mathrm{n}=111)$ & $\mathrm{p}$ \\
\hline Cutaneous system involvement & $37(100)$ & $110(99.1)$ & n.s. \\
\hline Maculopapular exanthem & - & $19(17.1)$ & 0.007 \\
\hline Urticaria & $23(62.2)$ & $51(45.9)$ & n.s. \\
\hline Angioedema & $29(78.4)$ & $63(56.8)$ & 0.019 \\
\hline Conjunctivitis & $2(5.4)$ & $1(0.9)$ & n.s. \\
\hline Gastrointestinal system involvement & $2(5.4)$ & $6(5.4)$ & n.s. \\
\hline Nausea/vomiting & - & $5(4.6)$ & n.s. \\
\hline Cramping stomach ache & $2(5.4)$ & $1(0.9)$ & n.s. \\
\hline Respiratory system involvement & $11(29.7)$ & $7(6.3)$ & $<0.001$ \\
\hline Rhinorrhoea & $1(2.7)$ & $0(-)$ & n.s. \\
\hline Sneezing & $1(2.7)$ & $0(-)$ & n.s. \\
\hline Nasal obstruction & $2(5.4)$ & $2(1.8)$ & n.s. \\
\hline Rhinitis & $2(5.4)$ & $2(1.8)$ & n.s. \\
\hline Hoarseness & $5(13.5)$ & $1(0.9)$ & 0.004 \\
\hline Cough & $7(18.9)$ & $1(0.9)$ & $<0.001$ \\
\hline Wheezing & $1(2.7)$ & $1(0.9)$ & n.s. \\
\hline Dyspnoea & $10(27)$ & $7(6.4)$ & 0.001 \\
\hline Cyanosis & $4(10.8)$ & - & 0.003 \\
\hline Cardiovascular system involvement & - & - & n.s. \\
\hline Psychiatric symptoms & $2(5.4)$ & $8(7.2)$ & n.s. \\
\hline History of anaphylaxis & $12(32.4)$ & $8(7.2)$ & $<0.001$ \\
\hline \multicolumn{4}{|l|}{ Chronology of DHR } \\
\hline Immediate & $30(81.1)$ & $46(41.4)$ & $<0.001$ \\
\hline Non-immediate & 7 (18.9) & $65(58.6)$ & \\
\hline \multicolumn{4}{|l|}{ Route of drug administration } \\
\hline Enteral & $36(97.3)$ & $106(95.5)$ & n.s. \\
\hline Parenteral & $1(2.7)$ & $5(4.5)$ & n.s \\
\hline \multicolumn{4}{|l|}{ Culprit drugs of the reaction } \\
\hline Ibuprofen & $17(45.9)$ & $55(49.5)$ & n.s. \\
\hline Aspirin & $6(16.2)$ & $6(5.4)$ & 0.037 \\
\hline Paracetamol & $4(10.8)$ & $34(30.6)$ & 0.017 \\
\hline Ketoprofen & $1(2.7)$ & $1(0.9)$ & n.s. \\
\hline Dexketoprofen & $2(5.4)$ & - & n.s. \\
\hline Flurbiprofen & - & $2(1.8)$ & n.s. \\
\hline Naproxen & $1(2.7)$ & $2(1.8)$ & n.s. \\
\hline Metamizole & $5(13.5)$ & $8(7.2)$ & n.s. \\
\hline Diclofenac & $1(2.7)$ & $3(2.7)$ & n.s \\
\hline Consumption of single drug during the reaction & $32(86.5)$ & $60(54.1)$ & $<0.001$ \\
\hline Acute treatment for allergic drug reaction & $33(89.2)$ & $102(91.9)$ & n.s. \\
\hline Antihistamines & $30(81.1)$ & $93(84.5)$ & n.s. \\
\hline Corticosteroids & $22(59.5)$ & $47(42.7)$ & n.s. \\
\hline Adrenaline & $6(16.2)$ & $3(2.7)$ & 0.003 \\
\hline Bronchodilators & $5(13.5)$ & $1(0.9)$ & 0.001 \\
\hline Emergency service admission for DHR & $92(86.5)$ & $86(77.5)$ & n.s. \\
\hline Hospitalization for DHR & $4(11.4)$ & $6(5.4)$ & n.s. \\
\hline \multicolumn{4}{|l|}{ Interval between reaction and testing for DHR } \\
\hline 3 months & $21(56.8)$ & $71(65.1)$ & n.s. \\
\hline 6 months & $20(54.1)$ & $75(68.8)$ & n.s. \\
\hline 12 months & $26(70.3)$ & $87(79.8)$ & n.s. \\
\hline 24 months & $29(78.4)$ & $96(88.1)$ & n.s. \\
\hline
\end{tabular}


Table 1. (continued)

b Risk factors for reproducible NSAID-H regarding the clinical features in reaction history

\begin{tabular}{|c|c|c|c|c|c|c|}
\hline & \multicolumn{3}{|c|}{ Univariate logistic regression } & \multicolumn{3}{|c|}{ Multivariate logistic regression } \\
\hline & OR & $95 \%$ CI & $\mathrm{p}$ & OR & $95 \% \mathrm{CI}$ & $\mathrm{p}$ \\
\hline NSAID-related immediate type of DHR & 5.836 & $2.36-14.42$ & $<0.001$ & 4.175 & $1.62-10.72$ & 0.003 \\
\hline Angioedema & 2.762 & $1.16-6.58$ & 0.022 & - & - & n.s. \\
\hline Respiratory system involvement & 6.286 & $2.22-17.79$ & 0.001 & 4.038 & $1.35-12.08$ & 0.013 \\
\hline
\end{tabular}

of allergic disease, which was more frequent in CIs compared to SRs ( 57.1 vs. $15.4 \%, p=0.031$; table $3 \mathrm{a}$ ). Five of the CIs had a history of suspected DHR with a single NSAID and 4 of the SRs had a history of suspected DHR with multiple NSAIDs. Considering the reactions in diagnostic tests and the signs and symptoms during severe anaphylactic NSAID-related reactions, reactions belonging to CIs were more frequently characterized by angioedema compared to those of SRs ( 81.3 vs. $46.2 \%, \mathrm{p}=$ 0.019 ; table $3 \mathrm{~b}$ ), whereas the rates of cutaneous or respiratory system involvement were similar between the two groups. Patients with NSAID-H were further classified as SNIUA and/or SNIUAA ( $\mathrm{n}=13)$, NIUA $(\mathrm{n}=7)$, NECD $(\mathrm{n}=2)$ and NERD $(\mathrm{n}=1)$ according to the ENDA/ GA $^{2}$ LEN classification system [10] and the classification by Caimmi et al. [9] (online suppl. table S1). There were no patients belonging to the SNIDR group. Four CIs could not be categorized according to either classification system, and one SR could not be categorized according to the ENDA/GA²LEN classification system (table 2).

\section{Discussion}

In this study, the characteristics of children and adolescents with suspected NSAID-H were comprehensively evaluated in terms of both the clinical features of the reactions and the characteristics of phenotypes of NSAID-H. The occurrence of reproducible NSAID-H was proven in $27 \%$ of the patients and $25 \%$ of the reactions. With respect to the clinical patterns, NSAID-hypersensitive patients in the paediatric age group were classified in detail. It is important to note that the NSAID$\mathrm{H}$ classifications based on adult data in the guidelines did not exactly fit the clinical patterns of the children and adolescents in our study.

NSAID-H comprises an important portion of DHRs $[4-6,25]$. Although $\beta$-lactam antibiotics have been the most frequently involved drugs in DHRs during childhood [26, 27], current evidence is increasing in relation to reproducible NSAID-H and related cross-reactivity in this age group [28]. According to diagnostic tests, the rates for reproducible NSAID-H are defined as 68 and $29 \%$, respectively, among children and adolescents with a suspected NSAID-related reaction history $[12,13]$. These results are significantly higher than the rates of reproducible drug hypersensitivity in children with a suspected $\beta$-lactam-related reaction history [29]. The frequency of NSAID-H in patients might vary in different studies in relation to geographic regions, the chemical structure and frequency of delivery of the NSAIDs involved, and the methodology used. In our study, NSAID-H frequency was found to be $25 \%$, which is much lower than in the study by Hassani et al. [30], in which NSAID-H frequency was found to be $49 \%$ based on OPTs or clinical history alone. In our study, reproducible NSAID-H and single or cross-reactivity diagnoses were based on skin or challenge tests, except for in patients with 'severe anaphylaxis'. This methodology increases the reliability of the data. Differences in geographical regions, ethnic origin and genetic factors of the study population may also account for the differences in clinical features of NSAID-hypersensitive patients. For example, very recent data suggest that single reactors are more frequently atopic [31]. Furthermore, it was shown that house dust mite sensitization was frequently pronounced in CI NSAID-hypersensitive Spanish and Venezuelan children $[12,32]$ and adults $[16$, 33]. This observation was not made in our study. On the other hand, in our study, the occurrence of angioedema during the reaction was more frequently associated with cross-intolerance. This was also the case in the study by Zambonino et al. [12], although the difference between CIs and SRs did not reach statistical significance. In addition, there is a well-known unique clinical entity labelled 'sole facial angioedema' described in atopic CI NSAIDhypersensitive children [6]. 
Table 2. Classification of NSAID-hypersensitive patients according to history and positive diagnostic tests in relation to the ENDA classification and the classification by Caimmi et al. [9]

\begin{tabular}{|c|c|c|c|c|c|c|c|c|c|c|c|c|c|}
\hline 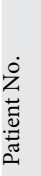 & 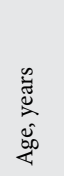 & $\frac{\tilde{c}}{\mathfrak{s}}$ & 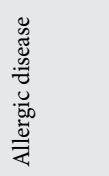 & 六 & 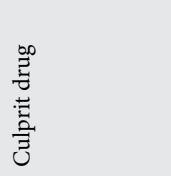 & 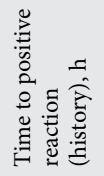 & 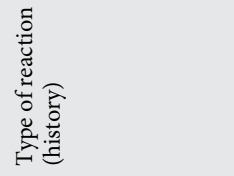 & 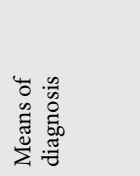 & 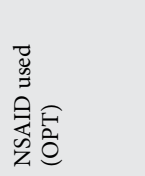 & 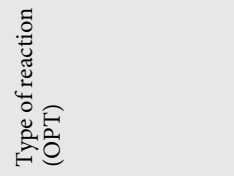 & 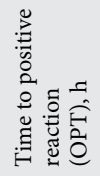 & 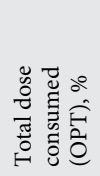 & 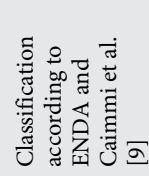 \\
\hline 1 & 15 & SR & AR & DP-DF & Ibuprofen & $\leq 1$ & $\mathrm{U}, \mathrm{AO}$, rhinitis & OPT & Ibuprofen & $\begin{array}{l}\mathrm{U}, \mathrm{AO} \text {, conjunctivitis, } \\
\text { rhinitis }\end{array}$ & 0.5 & 55 & SNIUA \\
\hline 2 & 6 & NA & - & - & Ibuprofen & $\leq 1$ & $\mathrm{U}, \mathrm{AO}$, hoarseness & $\begin{array}{l}\text { Severe } \\
\text { anaphylaxis }\end{array}$ & Ibuprofen & & & & NA \\
\hline 3 & 13 & SR & Asthma & - & ASA & $\leq 1$ & AO, dyspnoea & OPT & ASA & $\mathrm{AO}$ & 1 & 100 & SNIUA \\
\hline 4 & 17.3 & $\mathrm{SR}$ & - & - & Paracetamol & $\leq 1$ & $\mathrm{U}$ & OPT & Paracetamol & $\mathrm{U}$ & 0.25 & 100 & SNIUA \\
\hline 5 & 10.3 & $\mathrm{CI}$ & - & - & ASA & 2 & $\mathrm{AO}, \mathrm{U}$ & $\begin{array}{l}\text { OPT } \\
\text { OPT }\end{array}$ & $\begin{array}{l}\text { ASA } \\
\text { Ibuprofen }\end{array}$ & $\begin{array}{l}\mathrm{AO},>15 \% \downarrow \text { in } \mathrm{FEV}_{1} \\
\mathrm{AO}, \mathrm{U},>15 \% \downarrow \\
\text { in } \mathrm{FEV}_{1}\end{array}$ & $\begin{array}{l}4.5 \\
4\end{array}$ & $\begin{array}{l}20 \\
40\end{array}$ & Unclassified $^{1}$ \\
\hline 6 & 7.4 & SR & Asthma & & Ketoprofen & $\leq 1$ & $\mathrm{U}$ & OPT & Ketoprofen & $\mathrm{U}$ & 1 & 20 & SNIUA \\
\hline $7^{2}$ & 8.5 & $\mathrm{SR}$ & - & - & Ibuprofen & $\leq 1$ & $\mathrm{U}, \mathrm{AO}$ & OPT & Ibuprofen & $>15 \% \downarrow \mathrm{FEV}_{1}$ & 1 & 35 & SNIUAA \\
\hline 8 & 16.1 & $\mathrm{CI}$ & - & - & $\begin{array}{l}\text { ASA } \\
\text { Paracetamol } \\
\text { Metamizole }\end{array}$ & $\begin{array}{l}3 \\
4 \\
4\end{array}$ & $\begin{array}{l}\mathrm{AO} \\
\mathrm{AO} \\
\mathrm{AO}\end{array}$ & $\begin{array}{l}\text { OPT } \\
\text { OPT } \\
\text { OPT } \\
\text { OPT }\end{array}$ & $\begin{array}{l}\text { ASA } \\
\text { Paracetamol } \\
\text { Metamizole } \\
\text { Nimesulide }\end{array}$ & $\begin{array}{l}\mathrm{AO} \\
\mathrm{AO} \\
\mathrm{AO} \\
\mathrm{AO}\end{array}$ & $\begin{array}{l}4 \\
6 \\
6 \\
8\end{array}$ & $\begin{array}{l}100 \\
100 \\
100 \\
100\end{array}$ & NIUA \\
\hline 9 & 5.5 & SR & - & - & Paracetamol & 3 & $\mathrm{U}$ & OPT & Paracetamol & $\mathrm{U}$ & 5 & 100 & Unclassified $^{3}$ \\
\hline 10 & 9.4 & CI & - & - & $\begin{array}{l}\text { Ibuprofen } \\
\text { Metamizole }\end{array}$ & $\begin{array}{l}1 \\
1\end{array}$ & $\begin{array}{l}\mathrm{AO} \\
\mathrm{AO}\end{array}$ & $\begin{array}{l}\text { OPT } \\
\text { OPT } \\
\text { OPT }\end{array}$ & $\begin{array}{l}\text { Ibuprofen } \\
\text { Metamizole } \\
\text { ASA }\end{array}$ & $\begin{array}{l}\mathrm{AO}, \mathrm{U} \\
\mathrm{AO}, \mathrm{U} \\
\mathrm{AO}\end{array}$ & $\begin{array}{l}1 \\
1 \\
1\end{array}$ & $\begin{array}{l}60 \\
60 \\
60\end{array}$ & NIUA \\
\hline 11 & 7.8 & CI & Asthma & DP-DF & $\begin{array}{l}\text { ASA } \\
\text { Ibuprofen }\end{array}$ & $\begin{array}{l}\leq 1 \\
\leq 1\end{array}$ & $\begin{array}{l}\mathrm{AO} \\
\mathrm{U}, \mathrm{AO}\end{array}$ & $\begin{array}{l}\text { OPT } \\
\text { OPT }\end{array}$ & $\begin{array}{l}\text { ASA } \\
\text { Ibuprofen }\end{array}$ & $\begin{array}{l}\mathrm{AO} \\
\mathrm{AO}, \text { conjunctivitis }\end{array}$ & $\begin{array}{l}0.5 \\
0.5\end{array}$ & $\begin{array}{l}100 \\
100\end{array}$ & NIUA \\
\hline 12 & 5.2 & $\mathrm{CI}$ & Asthma & DP-DF & $\begin{array}{l}\text { Metamizole } \\
\text { - }\end{array}$ & $\leq 1$ & $\mathrm{U}, \mathrm{AO}$ & $\begin{array}{l}\text { OPT } \\
\text { OPT }\end{array}$ & $\begin{array}{l}\text { Metamizole } \\
\text { ASA }\end{array}$ & $\begin{array}{l}\mathrm{AO}, \mathrm{U}, \text { conjunctivitis } \\
\mathrm{AO}, \mathrm{U}\end{array}$ & $\begin{array}{l}0.5 \\
0.5\end{array}$ & $\begin{array}{l}55 \\
45\end{array}$ & NIUA \\
\hline 13 & 5.1 & SR & - & - & Ibuprofen & $\leq 1$ & $\mathrm{AO}$ & OPT & Ibuprofen & $\mathrm{AO}$ & 1 & 100 & SNIUA \\
\hline 14 & 5.1 & SR & $\mathrm{AR}$ & Pollen & Ibuprofen & $\leq 1$ & $\mathrm{AO}, \mathrm{U}$ & OPT & Ibuprofen & $\mathrm{U}$ & 1 & 100 & SNIUA \\
\hline 15 & 13 & SR & - & & Metamizole & $\leq 1$ & $\mathrm{U}, \mathrm{AO}$, dyspnoea & Skin test & Metamizole & & & & SNIUAA \\
\hline 16 & 4 & NA & $\mathrm{AR}$ & DP-DF & Ibuprofen & $\leq 1$ & $\begin{array}{l}\mathrm{U}, \mathrm{AO} \text {, hoarseness, } \\
\text { dyspnoea }\end{array}$ & $\begin{array}{l}\text { Severe } \\
\text { anaphylaxis }\end{array}$ & & & & & NA \\
\hline 17 & 17 & NA & - & - & Naproxen & $\leq 1$ & $\begin{array}{l}\text { U, AO, hoarseness, } \\
\text { dyspnoea, wheezing, } \\
\text { cough, rhinitis }\end{array}$ & $\begin{array}{l}\text { Severe } \\
\text { anaphylaxis }\end{array}$ & & & & & NA \\
\hline \multirow[t]{2}{*}{18} & 4.7 & $\mathrm{CI}$ & - & - & Ibuprofen & $\leq 1$ & $\begin{array}{l}\text { U, cough, hoarseness, } \\
\text { dyspnoea, cyanosis }\end{array}$ & $\begin{array}{l}\text { Severe } \\
\text { anaphylaxis }\end{array}$ & & & & & Unclassified $^{3}$ \\
\hline & & & & & Metamizole & $\leq 1$ & $\begin{array}{l}\text { U, cough, hoarseness, } \\
\text { dyspnoea, cyanosis }\end{array}$ & $\begin{array}{l}\text { Severe } \\
\text { anaphylaxis }\end{array}$ & & & & & \\
\hline 19 & 10 & CI & - & - & $\begin{array}{l}\text { Ibuprofen } \\
\text { ASA }\end{array}$ & $\begin{array}{l}\leq 1 \\
\leq 1\end{array}$ & $\begin{array}{l}\mathrm{AO} \\
\mathrm{AO}\end{array}$ & $\begin{array}{l}\text { OPT } \\
\text { OPT }\end{array}$ & $\begin{array}{l}\text { Ibuprofen } \\
\text { ASA }\end{array}$ & $\begin{array}{l}\mathrm{AO} \\
\mathrm{AO}\end{array}$ & $\begin{array}{l}1 \\
1\end{array}$ & $\begin{array}{l}60 \\
50\end{array}$ & NIUA \\
\hline 20 & 7.8 & SR & - & - & Ibuprofen & 3 & $\mathrm{U}, \mathrm{AO}$ & OPT & Ibuprofen & $\mathrm{U}$ & 0.5 & 100 & SNIUAA \\
\hline \multirow[t]{2}{*}{21} & 12.8 & CI & $\begin{array}{l}\text { Asthma, } \\
\text { nasal } \\
\text { polyposis }\end{array}$ & - & ASA & $\leq 1$ & Cough, dyspnoea & $\begin{array}{l}\text { Severe } \\
\text { anaphylaxis }\end{array}$ & & & & & NERD \\
\hline & & & & & Dexketoprofen & $\leq 1$ & $\begin{array}{l}\text { Cough, dyspnoea, } \\
\text { cyanosis }\end{array}$ & $\begin{array}{l}\text { Severe } \\
\text { anaphylaxis }\end{array}$ & & & & & \\
\hline \multirow[t]{2}{*}{22} & 10 & CI & $\mathrm{CU}, \mathrm{AR}$ & $\begin{array}{l}\text { Pollen } \\
\text { animal } \\
\text { dander }\end{array}$ & Ibuprofen & & $\mathrm{AO}$ & OPT & Ibuprofen & $\mathrm{AO}$ & 4 & 100 & NECD \\
\hline & & & & & - & & & OPT & ASA & $\mathrm{AO}$ & 0.6 & 100 & \\
\hline
\end{tabular}


Table 2. (continued)

\begin{tabular}{|c|c|c|c|c|c|c|c|c|c|c|c|c|c|}
\hline 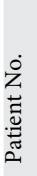 & 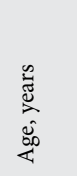 & ্ָড & 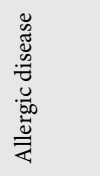 & 苍 & 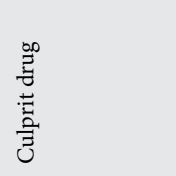 & 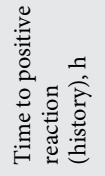 & 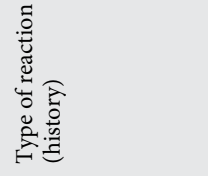 & 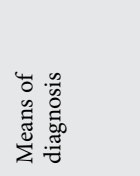 & 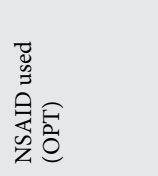 & 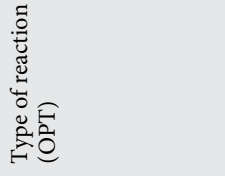 & 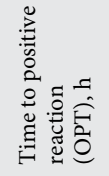 & 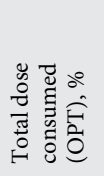 & 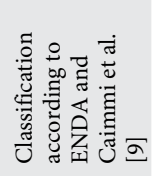 \\
\hline 23 & 9.7 & CI & $\mathrm{CU}$ & - & Dexketoprofen & $\leq 1$ & $\begin{array}{l}\mathrm{U}, \mathrm{AO} \text {, dyspnoea, } \\
\text { hoarseness, stridor }\end{array}$ & $\begin{array}{l}\text { Severe } \\
\text { anaphylaxis } \\
\text { OPT }\end{array}$ & $\begin{array}{l}\text { Dexketoprofen } \\
\text { ASA }\end{array}$ & $\mathrm{U},>15 \% \downarrow$ in $\mathrm{FEV}_{1}$ & 1 & 1 & Unclassified $^{3}$ \\
\hline 24 & 9.5 & CI & $\mathrm{CU}$ & - & $\begin{array}{l}\text { Ibuprofen } \\
-\end{array}$ & $\leq 1$ & $\mathrm{U}, \mathrm{AO}$ & $\begin{array}{l}\text { OPT } \\
\text { OPT }\end{array}$ & $\begin{array}{l}\text { Ibuprofen } \\
\text { ASA }\end{array}$ & $\begin{array}{l}\mathrm{U}, \mathrm{AO},>15 \% \downarrow \\
\text { in } \mathrm{FEV}_{1} \\
\mathrm{U}, \mathrm{AO} \text {, cough, } \\
\text { stridor, wheezing, } \\
>15 \% \downarrow \text { in } \mathrm{FEV}_{1}\end{array}$ & $\begin{array}{l}1 \\
0.5\end{array}$ & $\begin{array}{l}100 \\
60\end{array}$ & Unclassified $^{3}$ \\
\hline 25 & 11.8 & $\mathrm{CI}$ & $\mathrm{CU}$ & - & $\begin{array}{l}\text { Ibuprofen } \\
-\end{array}$ & $\leq 1$ & $\mathrm{AO}$ & $\begin{array}{l}\text { OPT } \\
\text { OPT }\end{array}$ & $\begin{array}{l}\text { Ibuprofen } \\
\text { ASA }\end{array}$ & $\begin{array}{l}\mathrm{AO} \\
\mathrm{AO}\end{array}$ & $\begin{array}{l}1.5 \\
1\end{array}$ & $\begin{array}{l}65 \\
65\end{array}$ & NECD \\
\hline 26 & 2.3 & SR & - & - & Ibuprofen & $\leq 1$ & $\mathrm{U}, \mathrm{AO}$ & OPT & Ibuprofen & $\mathrm{U}, \mathrm{AO}$ & 1 & 100 & SNIUA \\
\hline 27 & 10.8 & $\mathrm{CI}$ & Asthma & & $\begin{array}{l}\text { Ibuprofen } \\
-\end{array}$ & & $\mathrm{AO}$ & $\begin{array}{l}\text { OPT } \\
\text { OPT }\end{array}$ & $\begin{array}{l}\text { Ibuprofen } \\
\text { ASA }\end{array}$ & $\begin{array}{l}\mathrm{AO} \\
\mathrm{AO},>15 \% \downarrow \text { in } \mathrm{FEV}_{1} \text {, } \\
\text { cough, wheezing }\end{array}$ & $\begin{array}{l}1 \\
1\end{array}$ & $\begin{array}{l}30 \\
25\end{array}$ & NIUA \\
\hline 28 & 5.75 & SR & - & - & Ibuprofen & 1 & $\mathrm{U}, \mathrm{AO}$, dyspnoea & OPT & Ibuprofen & $\mathrm{U}$ & 1 & 40 & SNIUAA \\
\hline 29 & 5.1 & $\mathrm{CI}$ & - & - & Paracetamol & 6 & $\mathrm{U}$ & $\begin{array}{l}\text { OPT } \\
\text { OPT } \\
\text { OPT }\end{array}$ & $\begin{array}{l}\text { Paracetamol } \\
\text { Ibuprofen } \\
\text { ASA }\end{array}$ & $\begin{array}{l}\mathrm{U} \\
\mathrm{U} \\
\mathrm{U}\end{array}$ & $\begin{array}{l}2 \\
3 \\
3\end{array}$ & $\begin{array}{l}100 \\
100 \\
100\end{array}$ & NIUA \\
\hline 30 & 15.7 & SR & - & - & Diclofenac & 1 & $\mathrm{AO}$ & OPT & Diclofenac & $\mathrm{AO}$ & 1 & 100 & SNIUAA \\
\hline
\end{tabular}

One of the advantages of this study is that spirometry was used periodically during OPTs to monitor the patients. As the first sign of a positive challenge test, a fall in $\mathrm{FEV}_{1}$ was observed with the aid of close monitoring. As soon as a fall in $\mathrm{FEV}_{1}$ was noticed, the OPT was ceased and these patients were treated. The symptoms related to other system involvements occurred during the followup after the end of OPTs in these patients. A fall in FEV 1 was a warning sign (even in the absence of respiratory symptoms) not to continue with extra doses to complete the provocation test in patients 5, 23, 24 and 27 (table 2), who might have ended up with more severe and longlasting reactions. The rate of adrenaline injection was much lower than in the other studies [12]. We think that close monitoring with spirometry is a valuable method for preventing severe hypersensitivity reactions when performing OPTs with NSAIDs.

Cross-reactivity was determined according to the results of aspirin challenges in NSAID-hypersensitive patients, as recommended by the current guidelines $[3,10]$.
Aspirin was introduced to medicine more than a century ago and has since been widely used for pain relief [34]. Ibuprofen and paracetamol are more widely preferred and used as over-the-counter medications for the management of fever and/or mild-to-moderate pain in children $[1,35]$ due to the association of aspirin with Reye's syndrome [36]. Aspirin, however, is a strong COX-1 inhibitor and was used during the OPTs in this study when the children were in a healthy state (i.e. when they did not have symptoms of a flu-like disease and were not at risk for Reye's syndrome) [37]. The determination of crossreactivity or SR in NSAID-hypersensitive children in relation to aspirin provocation is an objective method compared to classification according to history. It is important to note that 5 CIs had a history of reaction with a single NSAID and 4 SRs had suspected DHR histories with multiple NSAIDs.

In this study, using a further step than used in the previously published reports $[12,13]$, SR and CI patients in the paediatric age group were categorized in relation to 
Table 3. Demographic and clinical features of NSAID-H

a Demographic and clinical characteristics of patients with NSAID-H according to SR and CI

\begin{tabular}{lccc}
\hline & $\mathrm{SR}(\mathrm{n}=13)$ & $\mathrm{CI}(\mathrm{n}=14)$ & $\mathrm{p}$ \\
\hline Male gender & $9(69.2)$ & $9(64.3)$ & $\mathrm{n} . s$. \\
Age at referral & $7.8(5.3-14.4)$ & $10.0(7.1-11.1)$ & n.s. \\
Atopy & $2(15.4)$ & $3(21.4)$ & n.s. \\
House dust mite & $1(7.7)$ & $2(14.3)$ & n.s. \\
Pollen & $1(7.7)$ & $1(7.1)$ & n.s. \\
\hline Food & - & - & NA \\
Animal dander & - & $1(7.1)$ & n.s. \\
Mould & - & $2(14.3)$ & n.s. \\
Allergic disease & $4(30.8)$ & $5(35.7)$ & n.s. \\
Asthma & $2(15.4)$ & $4(28.6)$ & n.s. \\
\hline Allergic rhinitis & $2(15.4)$ & $1(7.1)$ & n.s. \\
Food allergy & - & - & NA \\
Chronic or recurrent urticaria & - & $3(21.4)$ & n.s. \\
Concomitant chronic disease & $2(15.7)$ & $1(7.1)$ & n.s. \\
Concomitant chronic drug consumption & $1(7.7)$ & $1(7.1)$ & n.s. \\
\hline History of DHR with a single NSAID & $9(69.2)$ & $5(35.7)$ & n.s. \\
History of DHR with multiple NSAIDs & $4(30.8)$ & $9(64.3)$ & n.s. \\
Family history of allergic disease & $2(15.4)$ & $8(57.1)$ & 0.031 \\
Family history of drug hypersensitivity & $3(23.1)$ & $2(14.3)$ & n.s. \\
Total IgE & $129(49.1-267)$ & $60.8(60.8-129.8)$ & n.s. \\
\hline Eosinophil, \% & $2.5(1.3-4.4)$ & $2.6(1.0-3.8)$ & n.s. \\
FEV & $107.7 \pm 10.2$ & $97.1 \pm 10.4$ & n.s. \\
\hline
\end{tabular}

Values are either $\mathrm{n}(\%)$, median (interquartile range) or mean \pm standard deviation. n.s. = Non-significant; NA = not applicable.

b Clinical features of reproducible NSAID-H reactions (reactions during OPT and physician-diagnosed anaphylaxis) according to SR and CI

\begin{tabular}{|c|c|c|c|}
\hline Clinical features & $\mathrm{SR}(\mathrm{n}=13)$ & $\mathrm{CI}(\mathrm{n}=32)$ & $\mathrm{p}$ \\
\hline Cutaneous system involvement & $11(91.7)$ & $28(87.5)$ & n.s. \\
\hline Urticaria & $9(69.2)$ & $13(40.6)$ & n.s. \\
\hline Angioedema & $6(46.2)$ & $26(81.3)$ & 0.019 \\
\hline Maculopapular exanthem & - & - & NA \\
\hline Conjunctivitis & $1(7.7)$ & $4(12.5)$ & n.s. \\
\hline Respiratory system involvement & $2(16.7)$ & $11(34.4)$ & n.s. \\
\hline Rhinitis & $1(7.7)$ & - & n.s. \\
\hline Cough & - & $6(18.8)$ & n.s. \\
\hline Hoarseness & - & $2(6.5)$ & n.s. \\
\hline $15 \%$ decrease in $\mathrm{FEV}_{1}^{\mathrm{a}}$ & $1(12.5)$ & $6(27.3)$ & n.s. \\
\hline Gastrointestinal system involvement & - & $2(6.5)$ & n.s. \\
\hline Cutaneous and respiratory system involvement & $1(7.7)$ & $9(28.1)$ & n.s. \\
\hline Chronology of DHR according to history & & & n.s. \\
\hline Immediate & $10(76.9)$ & $17(81.0)$ & \\
\hline Non-immediate & $3(23.1)$ & $4(19.0)$ & \\
\hline
\end{tabular}

Values are $\mathrm{n}(\%)$. n.s. = Non-significant; $\mathrm{NA}=$ not applicable.

a The provocation tests with appropriate spirometric measurements were included $(n=31)$. 
the classification system found in globally accepted guidelines based on predominantly adult data $[3,10]$, and these findings were compared with the findings of Caimmi et al. [9]. One of the interesting findings was the involvement of respiratory system-related severe signs and symptoms in addition to cutaneous system involvement during reproducible NSAID-related reactions in 2 CI patients (patients 23 and 24, unclassified according to both classification systems; table 2) with a history of chronic spontaneous urticaria (CSU). This is not an expected finding because virtually all the CI adult patients with CSU exhibited exacerbation of cutaneous signs mostly as wheals and/or angioedema as a response during OPTs with COX-1 inhibitors. This phenotype was previously defined as 'aspirin-exacerbated cutaneous disease' (AECD) [38], which is now known as NECD [10]. In our previous study, in which AECD was defined in a group of children and adolescents with CSU, 1 of the children exhibited bronchospasm upon the administration of aspirin during an OPT, although all the other participants had apparent angioedema and/or exacerbation of urticarial lesions [24]. Respiratory involvement may be a feature of NSAID-hypersensitive children with concurrent CSU.

In addition, 2 other patients (patients 5 and 18) could not be classified because respiratory system involvement had taken place in addition to a cutaneous system response during their reproducible DHRs. It is notable that although anaphylaxis was reported previously in crossreactive patients without any underlying disease [6], this feature belonging to this phenotype does not exist in the ENDA/GA ${ }^{2} \mathrm{LEN}$ classification. One other patient (patient 9) could not be classified according to ENDA due to the fact that, although he was a single reactor, the reaction took place $5 \mathrm{~h}$ after the last drug intake instead of within an hour, which is expected for SNIUAA reactions according to ENDA.

One can argue that the exclusion of children less than 2 years of age at the time of diagnostic testing is a limitation to the study; however, due to ethical considerations, we did not perform the diagnostic tests with the culprit drug and aspirin in children below this age. Nevertheless, since the study took place over the course of more than 2 years and the youngest patient was 9 months old at the time of referral, all the patients could be evaluated at some point during the study period, and there were no significant differences in respect to the interval between referral and the time of diagnostic testing among patients with reactions of reproducible NSAID-H and those with reactions of NSAID tolerance (table 1a). Ad- ditionally, one may think that the rate of NSAID-H might be less than expected in children and adolescents. In studies involving adults performed in a particular type of NSAID-H, such as NERD [39] or CI NSAID-H with a history of more than two NSAIDs, the clinical history [40] is found to be highly predictive for reproducible NSAID-H. However, the rate of reproducible drug hypersensitivity found in this study comprised all the clinical phenotypes. Additionally, in this study the patients were questioned according to ENDA questionnaire, which is a widely used reliable tool for the evaluation of suspected DHRs [41], and only the patients with a relevant history were included.

In conclusion, reproducible NSAID-H was defined in 1 out of every 4 patients in the paediatric group with a suspected NSAID-related hypersensitivity reaction admitted to a tertiary referral centre. An anaphylaxis history with NSAIDs and reaction with only one group of drugs increases the personal risk of reproducible NSAID$\mathrm{H}$, while immediate DHR and respiratory symptoms during the reaction increases the risk of a reproducible NSAID-related reaction. As a result of a comprehensive evaluation of the patients and the clinical patterns of their reactions, it seems that NSAID-H exhibits different characteristics in the paediatric group, and that the classifications based on adult data may not fit NSAID-H in this age group in a few patients.

\section{Disclosure Statement}

All the authors declare that they have no potential conflicts of interest.

\section{References}

1 Dills R, Anderson LA, Pierce CA: The role of nonsteroidal anti-inflammatory drugs in pediatric patients. Pharmacol Res 2012;65:5-8.

2 Warner TD, Giuliano F, Vojnovic I, Bukasa A, Mitchell JA, Vane JR: Nonsteroid drug selectivities for cyclo-oxygenase-1 rather than cyclo-oxygenase- 2 are associated with human gastrointestinal toxicity: a full in vitro analysis. Proc Natl Acad Sci U S A 1999;96:75637568.

3 Kowalski ML, Asero R, Bavbek S, Blanca M, Blanca-Lopez N, Bochenek G, Campo P, Celik G, Cernadas J, Cortellini G, Gomes E, Niżankowska-Mogilnicka E, Romano A, Szczeklik A, Testi S, Torres MJ, Wöhrl S, Makowska J: Classification and practical approach to the diagnosis and management of hypersensitivity to nonsteroidal anti-inflammatory drugs. Allergy 2013;68:1219-1232. 
4 Messaad D, Sahla H, Benahmed S, Godard P, Bousquet J, Demoly P: Drug provocation tests in patients with a history suggesting an immediate drug hypersensitivity reaction. Ann Intern Med 2004;140:1001-1006.

5 Yilmaz O, Ertoy-Karagol HI, Bakirtas A: Non-steroidal antiinflammatory drug hypersensitivity in children. Asthma Allergy Immunol 2014;12:123-129.

6 Ayuso P, Blanca-Lopez N, Dona I, Torres MJ, Gueant-Rodriguez RM, Canto G, Sanak M, Mayorga C, Guéant JL, Blanca M, CornejoGarcía JA: Advanced phenotyping in hypersensitivity drug reactions to NSAIDs. Clin Exp Allergy 2013;43:1097-1109.

7 Quiralte J, Blanco C, Delgado J, Ortega N, Alcntara M, Castillo R, Anguita JL, Sáenz de San Pedro B, Carrillo T: Challenge-based clinical patterns of 223 Spanish patients with nonsteroidal anti-inflammatory-drug-inducedreactions. J Investig Allergol Clin Immunol 2007;17:182-188.

8 Stevenson DD, Sanchez-Borges M, Szczeklik A: Classification of allergic and pseudoallergic reactions to drugs that inhibit cyclooxygenase enzymes. Ann Allergy Asthma Immunol 2001;87:177-180.

9 Caimmi S, Caimmi D, Bousquet PJ, Demoly P: How can we better classify NSAID hypersensitivity reactions? - Validation from a large database. Int Arch Allergy Immunol 2012;159:306-312.

10 Kowalski ML, Makowska JS, Blanca M, Bavbek S, Bochenek G, Bousquet J, Bousquet P, Celik G, Demoly P, Gomes ER, Niżankowska-Mogilnicka E, Romano A, Sanchez-Borges M, Sanz M, Torres MJ, De Weck A, Szczeklik A, Brockow K: Hypersensitivity to nonsteroidal anti-inflammatory drugs (NSAIDs) - classification, diagnosis and management: review of the EAACI/ENDA and GA²LEN/HANNA. Allergy 2011;66:818-829.

11 Campo P, Ayuso P, Salas M, Plaza MC, Cornejo-Garcia JA, Dona I, Torres MJ, Blanca-López N, Canto G, Guéant JL, Sanak M, Blanca M: Mediator release after nasal aspirin provocation supports different phenotypes in subjects with hypersensitivity reactions to NSAIDs. Allergy 2013;68:1001-1007.

12 Zambonino MA, Torres MJ, Munoz C, Requena G, Mayorga C, Posadas T, Urda A, Blanca M, Corzo JL: Drug provocation tests in the diagnosis of hypersensitivity reactions to non-steroidal anti-inflammatory drugs in children. Pediatr Allergy Immunol 2013;24: 151-159.

13 Yilmaz O, Ertoy Karagol IH, Bakirtas A, Topal E, Celik GE, Demirsoy MS, Turktas I: Challenge-proven nonsteroidal anti-inflammatory drug hypersensitivity in children. Allergy 2013;68:1555-1561.

14 Corzo JL, Zambonino MA, Munoz C, Mayorga C, Requena G, Urda A, Gallego C, Blanca M, Torres MJ: Tolerance to COX-2 inhibitors in children with hypersensitivity to nonsteroidal anti-inflammatory drugs. $\mathrm{Br} \mathrm{J}$ Dermatol 2014;170:725-729.
15 Dona I, Blanca-Lopez N, Cornejo-Garcia JA, Torres MJ, Laguna JJ, Fernandez J, Rosado A, Rondón C, Campo P, Agúndez JA, Blanca M, Canto G: Characteristics of subjects experiencing hypersensitivity to non-steroidal antiinflammatory drugs: patterns of response. Clin Exp Allergy 2011;41:86-95.

16 Sanak M, Gielicz A, Bochenek G, Kaszuba M, Nizankowska-Mogilnicka E, Szczeklik A: Targeted eicosanoid lipidomics of exhaled breath condensate provide a distinct pattern in the aspirin-intolerant asthma phenotype. J Allergy Clin Immunol 2011;127:1141-1147. e2.

17 Demoly P, Adkinson NF, Brockow K, Castells M, Chiriac AM, Greenberger PA, Khan DA, Lang DM, Park HS, Pichler W, Sanchez-Borges M, Shiohara T, Thong BY: International consensus on drug allergy. Allergy 2014;69: 420-437.

18 Aberer W, Bircher A, Romano A, Blanca M, Campi P, Fernandez J, Brockow K, Pichler WJ, Demoly P, European Network for Drug Allergy (ENDA), EAACI Interest Group on Drug Hypersensitivity: Drug provocation testing in the diagnosis of drug hypersensitivity reactions: general considerations. Allergy 2003;58:854-863.

19 Cox L, Larenas-Linnemann D, Lockey RF, Passalacqua G: Speaking the same language: The World Allergy Organization Subcutaneous Immunotherapy Systemic Reaction Grading System. J Allergy Clin Immunol 2010;125:569-574.

20 Torres MJ, Barrionuevo E, Kowalski M, Blanca M: Hypersensitivity reactions to nonsteroidal anti-inflammatory drugs. Immunol Allergy Clin North Am 2014;34:507-524.

21 Szczeklik A: Analgesics. Chem Immunol Allergy 2010;95:170-179.

22 Gomez E, Blanca-Lopez N, Torres MJ, Requena G, Rondon C, Canto G, Blanca M, Mayorga C: Immunoglobulin E-mediated immediate allergic reactions to dipyrone: value of basophil activation test in the identification of patients. Clin Exp Allergy 2009;39:12171224.

23 Nizankowska-Mogilnicka E, Bochenek G, Mastalerz L, Swierczynska M, Picado C, Scadding G, Kowalski ML, Setkowicz M, Ring J, Brockow K, Bachert C, Wöhrl S, Dahlén B, Szczeklik A: EAACI/GA²LEN guideline: aspirin provocation tests for diagnosis of aspirin hypersensitivity. Allergy 2007;62:1111-1118.

24 Cavkaytar O, Arik Yilmaz E, Buyuktiryaki B, Sekerel BE, Sackesen C, Soyer OU: Challengeproven aspirin hypersensitivity in children with chronic spontaneous urticaria. Allergy 2015;70:153-160.

25 Rubio M, Bousquet PJ, Gomes E, Romano A, Demoly P: Results of drug hypersensitivity evaluations in a large group of children and adults. Clin Exp Allergy 2012;42:123-130.

26 Gamboa PM: The epidemiology of drug allergy-related consultations in Spanish Allergology services: Alergologica-2005. J Investig Allergol Clin Immunol 2009;19(suppl 2):45-50.
27 Rebelo Gomes E, Fonseca J, Araujo L, Demoly P: Drug allergy claims in children: from self-reporting to confirmed diagnosis. Clin Exp Allergy 2008;38:191-198.

28 Blanca-Lopez N, Dona I, Perkins JR, Canto G, Cornejo-Garcia JA, Blanca M: Multiple nonsteroidal anti-inflammatory drug-induced cutaneous disease: relevance, natural evolution and relationship with atopy. Int Arch Allergy Immunol 2014;164:147-148.

29 Zambonino MA, Corzo JL, Munoz C, Requena G, Ariza A, Mayorga C, Urda A, Blanca M, Torres MJ: Diagnostic evaluation of hypersensitivity reactions to beta-lactam antibiotics in a large population of children. Pediatr Allergy Immunol 2014;25:80-87.

30 Hassani A, Ponvert C, Karila C, Le Bourgeois M, De Blic J, Scheinmann P: Hypersensitivity to cyclooxygenase inhibitory drugs in children: a study of 164 cases. Eur J Dermatol 2008;18:561-565.

31 Asero R: Single NSAID hypersensitivity is associated with atopic status. Eur Ann Allergy Clin Immunol 2015;47:48-53.

32 Sanchez-Borges M, Capriles-Behrens E, Caballero-Fonseca F: Hypersensitivity to nonsteroidal anti-inflammatory drugs in childhood. Pediatr Allergy Immunol 2004;15:376380.

33 Sanchez-Borges M, Acevedo N, Caraballo L, Capriles-Hulett A, Caballero-Fonseca F: Increased total and mite-specific immunoglobulin $\mathrm{E}$ in patients with aspirin-induced urticaria and angioedema. J Investig Allergol Clin Immunol 2010;20:139-145.

34 Szczeklik A, Sanak M: The broken balance in aspirin hypersensitivity. Eur J Pharmacol 2006;533:145-155.

35 van den Anker JN: Optimising the management of fever and pain in children. Int J Clin Pract Suppl 2013;178:26-32.

36 Barzaga Arencibia Z, Choonara I: Balancing the risks and benefits of the use of over-thecounter pain medications in children. Drug Saf 2012;35:1119-1125.

37 Starko KM, Ray CG, Dominguez LB, Stromberg WL, Woodall DF: Reye's syndrome and salicylate use. Pediatrics 1980;66:859-864.

38 Mastalerz L, Setkowicz M, Sanak M, Szczeklik A: Hypersensitivity to aspirin: common eicosanoid alterations in urticaria and asthma. J Allergy Clin Immunol 2004;113:771-775.

39 Dursun AB, Woessner KA, Simon RA, Karasoy D, Stevenson DD: Predicting outcomes of oral aspirin challenges in patients with asthma, nasal polyps, and chronic sinusitis. Ann Allergy Asthma Immunol 2008;100: 420-425.

40 Blanca-Lopez N, J Torres M, Dona I, Campo P, Rondon C, Seoane Reula ME, Salas M, Canto G, Blanca M: Value of the clinical history in the diagnosis of urticaria/angioedema induced by NSAIDs with cross-intolerance. Clin Exp Allergy 2013;43:85-91.

41 Demoly P, Kropf R, Bircher A, Pichler WJ Drug hypersensitivity: questionnaire. Allergy 1999;54:999-1003. 